\title{
Ice age unfrozen: severe effect of the last interglacial, not glacial, climate change on East Asian avifauna
}

Feng Dong ${ }^{1,2+} \mathbb{D}^{\mathbb{D}}$, Chih-Ming Hung ${ }^{3 \dagger}$, Xin-Lei Li ${ }^{1}$, Jian-Yun Gao ${ }^{1}$, Qiang Zhang ${ }^{4}$, Fei Wu' ${ }^{1}$, Fu-Min Lei ${ }^{5^{*}}$, Shou-Hsien $\mathrm{Li}^{2^{*}}$ and Xiao-Jun Yang ${ }^{1 *}$

\begin{abstract}
Background: The glacial-interglacial cycles in the Pleistocene caused repeated range expansion and contraction of species in several regions in the world. However, it remains uncertain whether such climate oscillations had similar impact on East Asian biota, despite its widely recognized importance in global biodiversity. Here we use both molecular and ecological niche profiles on 11 East Asian avian species with various elevational ranges to reveal their response to the late Pleistocene climate changes.

Results: The ecological niche models (ENM) consistently showed that these avian species might substantially contract their ranges to the south during the Last Interglacial period $(L I G)$ and expanded their northern range margins through the Last Glacial Maximum (LGM), leading to the LGM ranges observed for all 11 species. Consistently, coalescent simulations based on 25-30 nuclear genes retrieved signatures of significant population growth through the last glacial period across all species studied. Climate statistics suggested that high climatic variability during the LIG and a relatively mild climate at the LGM potentially explained the historical population dynamics of these birds.

Conclusions: This is the first study based on multiple species and both lines of ecological niche profiles and genetic data to characterize the unique response of East Asian biota to late Pleistocene climate. The present study highlights regional differences in the evolutionary consequence of climate change during the last glacial cycle and implies that global warming might pose a great risk to species in this region given potentially higher climatic variation in the future analogous to that during the LIG.
\end{abstract}

Keywords: Coalescent simulations, Ecological niche modeling, East Asian birds, Pleistocene climate change, Last interglacial period, Last glacial maximum

\section{Background}

Recent glacial cycles have been well recognized as one of the major forces shaping patterns of global biodiversity [1-4]. It is widely perceived that species responded to the cyclical climatic changes in the Pleistocene by the

\footnotetext{
*Correspondence: leifm@ioz.ac.cn; t43028@ntnu.edu.tw; yangxj@mail.kiz.ac.cn

${ }^{\dagger}$ Equal contributors

${ }^{5}$ Key Laboratory of Zoological Systematics and Evolution, Institute of Zoology, Chinese Academy of Sciences, 1 Beichen West Rd., Chaoyang District, Beijing 100101, China

2Department of Life Science, National Taiwan Normal University, 88 Ting-chou Rd., Sec. 4, Taipei 116, Taiwan

${ }^{1}$ Kunming Institute of Zoology, Chinese Academy of Sciences, 32 Jiaochang Donglu Rd., Kunming, Yunnan, China

Full list of author information is available at the end of the article
}

repeated "expansion-contraction" of their ranges during the alternating glacial and interglacial periods [2]. For example, advancing ice sheets in the Pleistocene drove the contraction of temperate biota to refugia and the expansion of polar biota in glaciated regions such as Europe [1, 2], North America [5] and Antarctica [6]. Conversely, in unglaciated regions increasing aridity due to global cooling during glacial maxima led to range contraction in mesic-adapted species and range expansion in arid-adapted species, as reported in South America and Africa [7], Australia [8] and Sundaland [9]. It has been argued that the alternative warmer and wetter climate during interglacial periods caused the range changes in these regions into the reverse $[3,10]$. 
However, whether climate oscillations during the Pleistocene lead to cyclical range changes in the biota of East Asia, a biodiversity hotspot [11], has not been comprehensively assessed.

East Asia was not covered by ice sheets during the entire Pleistocene [12]. Palynological data indicate a southward contraction of subtropical vegetation at the Last Glacial Maximum (LGM; 19-26 thousand years ago, Ka) [11]. Despite confirmation by several ecological niche modeling (ENM) studies [13-15], other recent studies failed to find any significant impact of the LGM on the distributions of several plant and animal species in East Asia [16-22]; rather, some studies observed substantial range contraction during the warmer Last Interglacial period (LIG, 112-132 Ka) [18-24]. Given that severe range retraction can cause dramatic reductions in population [25], one might expect small effective population sizes $\left(N_{e}\right)$ in East Asian species because of either LGM or LIG contraction. By contrast, several genetic analyses found confounding effects, e.g. with demographic growth under a range contraction scenario [13] or with constant population size through Pleistocene glaciations [26]. Thus, it was hypothesized that Pleistocene glaciations might have had a minor impact on East Asian organisms [26]. However, such discrepancies may have been caused by limitations in study design, for example, with low power to detect population decline (e.g. bottleneck) based on limited number of loci [27], such as a single maternally inherited locus (e.g. mitochondrial or chloroplast DNA) $[16,28]$ or few, if any, nuclear genes $[17,26]$. In addition, previous studies only focused on one or few species precluding a comprehensive understanding of community level dynamics. Therefore, analyses based on multiple species and multiple loci are required to robustly test for demographic dynamics of biota in this region [29].

In the present study, we used ecological niche profiles and genetic data to examine the impact of the last interglacial-glacial cycle on 11 non-migrant bird species common in subtropical East Asia. These birds can be categorized into three classes with different elevational distribution ranges reflecting the breadth of their habitats (see details in Additional file 1: Table S1): five elevational generalists (elevational range: 0-4000 m; Aegithalos concinnus, Cettia fortipes, Leiothrix lutea, Pomatorhinus ruficollis, and Stachyridopsis ruficeps), four highland specialists (1000 - 4000 m; Fulvetta ruficapilla, Lioparus chrysotis, Parus monticolus, and Yuhina diademata) and two lowland specialists (mainly $0-1500 \mathrm{~m}$; Alcippe morrisonia and Spizixos semitorques). Given that their ranges are mostly confined to the subtropics (south of $34^{\circ} \mathrm{N}$ ), these birds are likely to have been sensitive to historical environmental changes, presenting an ideal system to examine biological responses to late
Pleistocene climate in East Asia. Understanding their responses to historical climate change is also critical to predict the future fate of the East Asian biota under the ongoing global warming.

Because climate plays a primary and necessary role in species' range limitation [30], we first used ENM analyses to examine whether the birds' habitats were subject to regular glacial contraction and interglacial expansion during the last glacial cycle (i.e. the LIG, LGM and present day). Range dynamics (expansion or contraction) resulting from climate change are expected to have had pronounced genetic consequences in populations $[25$, 31]. So we further performed coalescent analyses based on 25-30 nuclear loci for each species to examine whether the last glaciation cycle had impacted population genetic variation and demographic dynamics of the 11 East Asian birds.

\section{Methods \\ Ecological niche modeling}

We used ENM analyses to model range dynamics between the LIG, LGM and Present. Raw occurrence records for each of the 11 species (see details in Additional file 2), following the taxonomy in the Handbook of the Birds of the World (HBW) series, were compiled from the eBird Basic Dataset (http://ebird.org/ content/ebird, accessed Aug 2015) and China Bird Report (http://www.birdreport.cn, accessed Aug 2015), and outliers from their known distributions were removed. To avoid spatial autocorrelation, the retained records were then rarefied at a $5-\mathrm{km}$ spatial resolution under a south Asian continent equidistant conic projection in SDMtoolbox 1.1c [32] (see dataset in Additional file 3), roughly equivalent to the resolution of climatic layers (e.g. 2.5 arc-minute resolution). Climate grids for the present and LGM (under the Community Climate System Model) were downloaded from the WorldClim website [33] (http://www.worldclim.org) with 2.5 arc-minute resolutions. The LIG model was initially obtained with a 30 arc-second resolution and then resampled to 2.5 arc-minute using a "NEAREST" algorithm using SDMtoolbox. The reasonability of study area extent is crucial for accuracy of ENM analyses and is difficult to determine [34]. Given present distributions, we set an enlarged area exceeding the mainland Oriental Region [35], sufficiency of which was verified by whether or not embracing the species' distribution changes across historical climate changes.

To reduce model overfitting associated with factor autocorrelation, highly correlated $(r>0.90)$ bioclimatic variables were identified and finally 10 variables were reserved, namely Bio_2 (mean diurnal range in temperature), Bio_3 (isothermality, monthly/ annual temperature range), Bio_5 (maximum temperature of 
warmest month), Bio_7 (temperature annual range), Bio_11 (mean temperature of coldest quarter), Bio_14 (precipitation of driest month), Bio_15 (precipitation seasonality, coefficient variation), Bio_16 (precipitation of wettest quarter), Bio_18 (precipitation of warmest quarter) and Bio_19 (precipitation of coldest quarter). In addition, winter records for species with significant seasonal migration (e.g. S. semitorques and C. fortipes, see details in Additional file 1: Table S1) were excluded from the downstream analyses to improve prediction accuracy. The present-day ENM for each species was created and then extrapolated to palaeoclimatic layers at the LGM and LIG in MAXENT 3.3.3 k [36]. Model parameters were trained with $75 \%$ of the occurrence records randomly sampled for each species and test by the other $25 \%$, except that for species (F. ruficapilla and L. chrysotis) with fewer occurrence records (e.g. <100) all data were used to train the models (see details in Additional file 1: Table S3). Two options in MAXENT were applied to reduce model over-prediction, with the maximum training sensitivity plus specificity (MTSS) threshold and the fadeby-clamping (i.e. to mitigate clamping issues during extrapolation among nonanalogous climates) procedure. Model performance was evaluated with the statistics of the area under the receiver operating characteristic curve (AUC).

\section{Climatic statistics}

To characterize the climate of the last glaciation cycle, we compared climatic variations among the LIG, LGM and present day, and those across latitudes at the LIG, by extracting bioclimatic values based on a spatially rarefied occurrence dataset combined from all 11 birds studied. All the occurrence records across species were first combined and then rarefied by a $5-\mathrm{km}$ distance, to approximate one point in one grid. Based on these points, values of the 10 bioclimatic variables used in above ENM analyses were extracted using DIVA-GIS 7.5 [37] and the significance of differences was calculated with a paired-sample T-test.

\section{Coalescent simulations}

Coalescent simulations were conducted to uncover demographic changes through time. For each species studied, 17-34 (typically 25-34, except 17-19 for F. ruficapilla, S. semitorques, and $P$. monticolus) individuals were sampled, a number sufficient to accurately estimate population size changes [38].

Genomic DNA was extracted using conventional proteinase $K$ digestion and phenol/chloroform extraction [39]. For each species, totally 25-31 nuclear loci (including introns and exons, see details in Additional file 1: Table S2) were amplified and sequenced for all samples using published primers and protocols [40-42]. The DNA sequences were compiled in SeqMan 7.1.0 (DNAStar Inc., Madison, WI) and were aligned in Clustal X 1.83 [43]. Nuclear genotypes were phased using PHASE 2.1.1 [44] with five runs for 1000 iterations. Genotypes with low phasing probability $(<0.60)$ were excluded from all subsequent analyses, considering their uncertainties [45]. Recombination within each locus was detected by three non-parametric methods (RDP, GENECONV and MAXCHI) with RDP 3.44 [46]. Evolutionary neutrality was tested using Tajima's $D$ [47] and Fu and Li's $D^{*}$ [48] statistics in DnaSP 5.10.01 [49].

Bayesian coalescent inference of demographic history was conducted using BEAST 1.8.2 [50] with model selection. For each species, five demographic models were considered, including four parametric models (constant, expansion, exponential and logistic growth) and the flexible Bayesian Skygrid model [51]. The margin likelihoods of each model were estimated using both stepping-stone and path sampling methods [52] based on three replicates of 500 million MCMC generations with the HKY substitution model and strict molecular clocks, and compared by $\log$ Bayes factor with values larger than three indicating a strong preference of one model against others [53]. Recent mounting evidence has suggested time-dependent rates of molecular evolution with faster rates over shorter time frames than what are calibrated by phylogenetic divergences, in some cases by half [54] to an order of magnitude [55, 56]. In present study, the BEAST analyses were first conducted with a fixing mean substitution rate across genes of $3.3 \times 10^{-9}$ substitutions per site per year $(\mathrm{s} / \mathrm{s} / \mathrm{y})$ for Passeriformes [57], and then rescaled using 5 -fold (i.e. $1.65 \times 10^{-8} \mathrm{~s} / \mathrm{s} /$ y) and 10-fold $\left(3.3 \times 10^{-9} \mathrm{~s} / \mathrm{s} / \mathrm{y}\right)$ faster rates, respectively, to test the sensitivity of the prior settings. Convergence for each run was visually inspected and diagnosed with an effective sample size $>200$ in Tracer 1.6 [58]. Final plotting of the best-fit demographic model for each species was generated based on the combined MCMC generations after discarding the first $10 \%$ as burn-in.

In addition, we tested population expansions using a Bayesian algorithm implemented in LAMARC 2.1.8 [59] by inferring exponential population growth rates. Positive growth rates would indicate a growing population, while negative values suggest population shrinkage. We performed one short MCMC run (1000 samples, 100 steps as interval and 10,000 samples as burn-in) followed by a longer one (10,000 samples, 100 steps as interval and 10,000 samples as burn-in) for each species with default model priors. To improve search performance, a heating scheme was used with one cold and three heated chains with default temperature settings. Convergence on the parameter estimates was visually inspected in Tracer 1.6 with an effective sample size $>200$. 


\section{Results}

After data filtering and spatial rarefication, 77-532 occurrence records for each bird were used in ENM reconstructions (see details in Additional file 1: Table S3). The resulted ENM for each species well encompassed historical distribution dynamics, indicating the reasonability of study area setting [34]. With high AUC scores (0.924-0.975, see details in Additional file 1: Table S3), the ENM analyses for all species clearly showed that the hindcasted area of suitable habitats for the 11 birds at the LGM were similar to those of the present day, whereas each species contracted its range southward to low-latitude areas at the LIG but with three different patterns (Fig. 1 and Additional file 4: Figure S1). That is, (1) the highland specialists contracted to the southern Heng-Duan Mountains in southwest China, (2) the lowland specialists retreated to coastal regions of southeast China and (3) the elevational generalists tended to survive at both of the two regions. Generalists had larger distribution ranges than specialists throughout the last glaciation cycle.

When compared to that at either the LGM or present, climate summary statistics during the LIG (Fig. 2a and b) showed both enlarged seasonal temperature and precipitation, being warmer in summers, wetter in wet seasons, colder in winters and drier in dry seasons (Additional file 5: Figure S2). In addition, the climatic variations increased with latitude in this region at the LIG (Fig. 2c and Additional file 6: Figure S3).

For the sequences of all the loci generated in the present study, no intra-locus recombination was

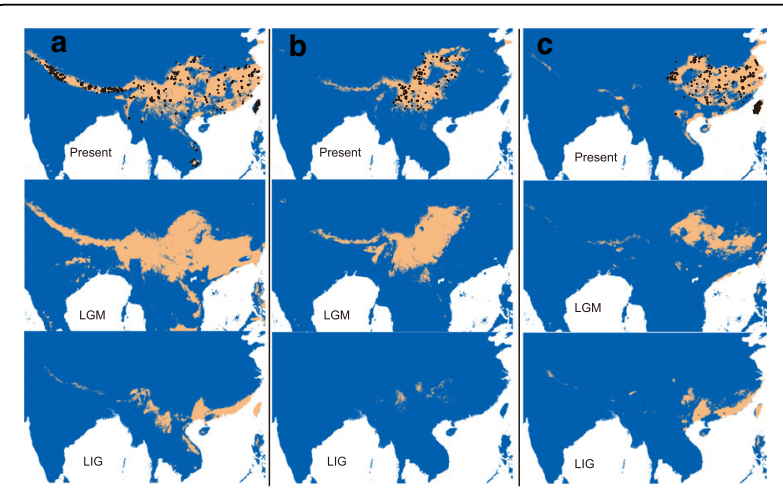

Fig. 1 The three patterns of ecological niche models (ENMs) and distribution dynamics for birds studied in the present study. (a) Aegithalos concinnus, (b) Yuhina diademata and (c) Spizixos semitorques. For each species, three time points were considered, i.e., the present day (Present), last glacial maximum (LGM; 26-19 thousand years ago, Ka), and last interglacial period (LIG; 112-132 Ka). Black dots show species occurrence records rarefied at a 1-km spatial resolution. To avoid over-prediction, the ENMs were transformed to binary (presence/ absence) distribution by a threshold of the maximum training sensitivity plus specificity (MTSS), with detailed logistic values specified in Additional file 1: Table S3 detected. For each species, 0-3 loci with significant values both in Tajima's $D$ and Fu and Li's $D^{*}$ statistics (see details in Additional file 1: Table S2) were conservatively excluded from subsequent analyses, despite the difficulty in distinguishing between demographic change and natural selection as the cause for the observed nonneutrality. Finally, a final dataset of 25-30 evolutionarily independent and neutral loci were employed for each bird species (Table 1 and Additional file 1: Table S2). All sequences generated in the current study were deposited in GenBank (accession numbers: KY434671-KY435354, KY437041-KY437069, KY597864-KY604704) and also provided in Additional file 7.

The favored models of multi-locus coalescent analyses using BEAST (Table 1) supported an overall post-LIG population growth leading to a $\sim 3-32$-fold increase in their effective population sizes up to the present day (see details in Additional file 8: Figure S4). Employment of different molecular rate levels resulted in distinct time spans for the observed population growths but with a consistent pattern of demographic growth from LIG to LGM (Fig. 3 and Additional file 8: Figure S4). This history of population expansion was further supported by large positive exponential population growth rates (254-873; Table 1) estimated using LAMARC. Across the 11 birds, continuous population growth started in two distinct phases. For example, with 5 -fold faster molecular rates, elevational generalists except $C$. fortipes and one lowland specialist (A. morrisonia) underwent population growth around $98-116 \mathrm{Ka}$, right after the LIG; whereas the other six species (the four highland and one lowland specialist and one generalist) grew around $40-64 \mathrm{Ka}$, at the middle of the last glacial period ( 12-112 Ka).

\section{Discussion}

In the present study, both our range and demographic analyses imply the contraction of the East Asian subtropical birds' populations at the LIG and a subsequent expansion through the LGM to the present. The results suggest that the glacial maximum might only have a minor impact on the demography of East Asian organisms in contrast to the potential severe effect of the last interglacial climate. The concordant patterns of change in the multiple species allow us to make a more general picture about late Pleistocene range shifts in East Asian avifauna, which was alluded to by previous studies based on one or a few species $[17,23,24]$.

The response pattern suggested by our present study stands in contrast to the prevailing view of cyclical range shifts for temperate species, which postulates glacial contraction and post-glacial expansion. These results also contradict the palynological analysis suggesting an 


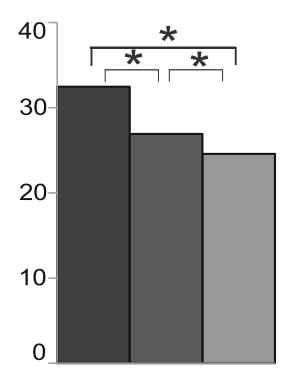

a

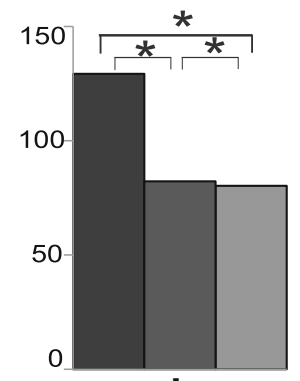

b

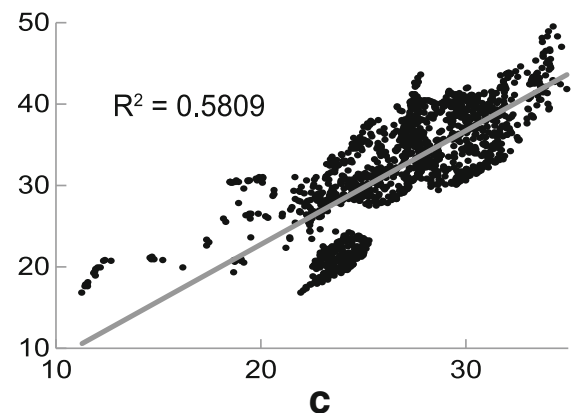

Fig. 2 Histograms indicating climatic comparisons. (a) Temperature annual range (Bio_7), (b) Precipitation seasonality (Bio_15) among LIG (black), LGM (dark grey) and Present (light grey) and (c) relations of temperature variations (Bio_7) (y axis) and latitudes ( $x$ axis) at LIG. The means of each variable was calculated based on 1506 occurrence records after spatial filtration at $1 \mathrm{~km}^{2}$ of all the combination records of 11 birds. The temperature data are in centigrade, precipitation is in millimeters and the latitudes are in degrees. The asterisk ${ }^{*}$ ) indicates $P \leq 0.001$ calculated with a paired-samples $T$ test

LGM contraction in East Asia. The power of palynological reconstructions might be compromised by the scarcity of pollen-fossil data, a problem prevalent in unglaciated regions in the Pleistocene [4]. For example, few pollen fossils from the LGM have been obtained in subtropical China [60].
The LIG has long been recognized as a climatic optimum for most mesic-adapted species [61], and fossil records suggest similar avifaunas between the LIG and the current interglacial period in temperate regions of Europe and North America [62]. However, our analyses revealed species' range and demographic contraction at

Table 1 Summary information for species studied, including species names, number of sampled individuals and loci, as well as log marginal likelihood for each demographic model. Best fitting models with log Bayes factor generally larger than 3 against others are highlighted in bold

\begin{tabular}{|c|c|c|c|c|c|c|c|c|}
\hline \multirow[t]{2}{*}{ Species } & \multirow[t]{2}{*}{ No. Inds ${ }^{a}$} & \multirow[t]{2}{*}{ No. Loc } & \multirow{2}{*}{$\frac{\text { Output of LAMARC analyses }}{g(95 \% \mathrm{Cl})^{c}}$} & \multicolumn{5}{|c|}{ Output of BEAST analyses ${ }^{d}$} \\
\hline & & & & Constant size & $\begin{array}{l}\text { Exponential } \\
\text { growth }\end{array}$ & $\begin{array}{l}\text { Logistic } \\
\text { growth }\end{array}$ & $\begin{array}{l}\text { Expansion } \\
\text { growth }\end{array}$ & $\begin{array}{l}\text { Bayesian } \\
\text { Skygrid }\end{array}$ \\
\hline Aegithalos concinnus & 29 & $25(25)$ & $873.09(623.44,919.20)$ & $\begin{array}{l}-18,381.02 / \\
-18,387.41\end{array}$ & $\begin{array}{l}-18,337.58 / \\
-18,345.80\end{array}$ & $\begin{array}{l}-18,335.44 / \\
-18,342.76\end{array}$ & $\begin{array}{l}-18,337.65 / \\
-18,344.41\end{array}$ & $\begin{array}{l}-18,328.25 / \\
-18,337.20\end{array}$ \\
\hline Alcippe morrisonia & 31 & $26(26)$ & $445.00(213.07,808.07)$ & $\begin{array}{l}-21,925.05 .24 / \\
-21,761.34\end{array}$ & $\begin{array}{l}-21,321.76 / \\
-21,334.32\end{array}$ & $\begin{array}{l}-21,310.73 / \\
-21,321.83\end{array}$ & $\begin{array}{l}-21,329.74 / \\
-21,340.07\end{array}$ & $\begin{array}{l}-21,319.53 / \\
-21,330.55\end{array}$ \\
\hline Cettia fortipes & 28 & $26(25)$ & $864.57(657.38,914.89)$ & $\begin{array}{l}-20,866.90 / \\
-20,871.83\end{array}$ & $\begin{array}{l}-20,816.09 / \\
-20,822.49\end{array}$ & $\begin{array}{l}-20,810.44 / \\
-20,817.28\end{array}$ & $\begin{array}{l}-20,813.41 / \\
-20,821.15\end{array}$ & $\begin{array}{l}-20,818.79 / \\
-20,825.96\end{array}$ \\
\hline Fulvetta ruficapilla & 17 & $27(25)$ & $254.87(-288.12,835.27)$ & $\begin{array}{l}-23,164.78 / \\
-23,166.04\end{array}$ & $\begin{array}{l}-23,157.21 / \\
-23,159.99\end{array}$ & $\begin{array}{l}-23,158.79 / \\
-23,160.72\end{array}$ & $\begin{array}{l}-23,154.82 / \\
-23,156.59\end{array}$ & $\begin{array}{l}-23,165.93 / \\
-23,167.89\end{array}$ \\
\hline Leiothrix lutea & 26 & $27(25)$ & $889.45(721.87,930.99)$ & $\begin{array}{l}-19,430.79 / \\
-19,436.22\end{array}$ & $\begin{array}{l}-19,371.60 / \\
-19,379.16\end{array}$ & $\begin{array}{l}-19,366.81 / \\
-19,374.85\end{array}$ & $\begin{array}{l}-19,373.72 / \\
-19,381.19\end{array}$ & $\begin{array}{l}-19,371.27 / \\
-19,378.37\end{array}$ \\
\hline Lioparus chrysotis & 25 & $26(26)$ & $691.00(119.92,867.68)$ & $\begin{array}{l}-22,793.63 / \\
-22,796.47\end{array}$ & $\begin{array}{l}-22,789.32 / \\
-22,792.89\end{array}$ & $\begin{array}{l}-22,777.02 / \\
-22,781.68\end{array}$ & $\begin{array}{l}-22,781.52 / \\
-22,786.17\end{array}$ & $\begin{array}{l}-22,558.18 / \\
-22,559.17\end{array}$ \\
\hline Parus monticolus & 19 & $28(26)$ & $839.81(-24.42,896.38)$ & $\begin{array}{l}-22,914.29 / \\
-22,916.07\end{array}$ & $\begin{array}{l}-22,902.45 / \\
-22,905.75\end{array}$ & $\begin{array}{l}-22,899.97 / \\
-22,902.93\end{array}$ & $\begin{array}{l}-22,903.01 / \\
-22,905.79\end{array}$ & $\begin{array}{l}-22,906.41 / \\
-22,910.13\end{array}$ \\
\hline Pomatorhinus ruficollis & 34 & $27(25)$ & $586.95(293.02,854.46)$ & $\begin{array}{l}-19,062.06 / \\
-19,070.21\end{array}$ & $\begin{array}{l}-19,037.46 / \\
-19,050.57\end{array}$ & $\begin{array}{l}-19,030.12 / \\
-19,042.18\end{array}$ & $\begin{array}{l}-19,033.39 / \\
-19,044.01\end{array}$ & $\begin{array}{l}-19,024.95 / \\
-19,037.02\end{array}$ \\
\hline Spizixos semitorques ${ }^{\mathrm{e}}$ & 26 & $26(26)$ & $835.62(259.03,881.86)$ & $\begin{array}{l}-19,240.68 / \\
-19,242.86\end{array}$ & $\begin{array}{l}-19,222.16 / \\
-19,224.94\end{array}$ & $\begin{array}{l}-19,221.68 / \\
-19,223.76\end{array}$ & $\begin{array}{l}-19,228.76 / \\
-19,231.84\end{array}$ & $\begin{array}{l}-19,229.73 / \\
-19,233.30\end{array}$ \\
\hline Stachyridopsis ruficeps & 31 & $31(30)$ & $842.18(431.79,890.58)$ & $\begin{array}{l}-25,752.35 / \\
-25,763.90\end{array}$ & $\begin{array}{l}-25,716.61 / \\
-25,729.62\end{array}$ & $\begin{array}{l}-25,707.27 / \\
-25,722.91\end{array}$ & $\begin{array}{l}-25,701.14 / \\
-25,715.47\end{array}$ & $\begin{array}{l}-25,718.02 / \\
-25,734.83\end{array}$ \\
\hline Yuhina diademata & 32 & $25(25)$ & $749.45(240.43,880.94)$ & $\begin{array}{l}-24,669.52 / \\
-24,677.78\end{array}$ & $\begin{array}{l}-24,653.90 / \\
-24,662.24\end{array}$ & $\begin{array}{l}-24,643.13 / \\
-24,654.81\end{array}$ & $\begin{array}{l}-24,654.13 / \\
-24,664.42\end{array}$ & $\begin{array}{l}-24,657.12 / \\
-24,665.48\end{array}$ \\
\hline
\end{tabular}

${ }^{a}$ number of individuals sampled for each species

${ }^{b}$ number of loci sampled for each species with that finally used in brackets

cthe most probable estimates of population growth rate for each species with $95 \%$ credibility intervals (Cl) in brackets

${ }^{d}$ log marginal likelihood estimates for different species and coalescent models, estimated using path sampling and step-stone procedures

ethis species has two equivalently best-fitted and general similar models, and the model with smallest log marginal likelihood (e.g., logistic growth) was shown in Fig. 2 


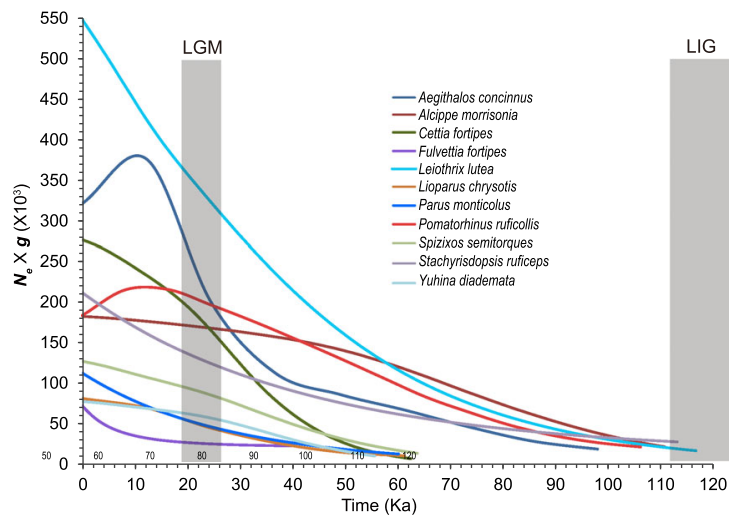

Fig. 3 Demographic reconstruction of the most favored models for each bird studied at 5-fold molecular rates. The colored plot lines represent median posterior estimates of the product of effective population size $\left(N_{e}\right)$ and generation time $(g)$. Times are in thousands of years before present (Ka). Timeframes are marked by grey areas. LIG, last interglacial period, 112-132 Ka; LGM, last glacial maximum, $\sim 19-26 \mathrm{Ka}$

this time, suggesting that the East Asian climate at the LIG had some significant evolutionary consequences. Climate summary statistics showed larger seasonal climatic variability at the LIG than the LGM or present (Fig. 2a and b), which increased with latitude in this region at the LIG (Fig. 2c and Additional file 6: Figure S3). This climatic scenario is consistent with results from recent simulation studies of LIG climate based on orbit parameters, which also showed that the larger temperature seasonality over East Asia during LIG might have resulted from seasonal fluctuations in incoming solar radiation [63]. Given the nature of the limited tolerance of subtropical species to climatic variations [64], the increased LIG climate seasonality at higher latitudes in East Asia might have caused the predicted southern contraction and declines in the study species' population during the LIG.

The three LIG southern contraction patterns among species (Additional file 4: Figure S1) might be associated with different environmental requirements (Additional file 1: Table S1). The asynchrony at population growth (Fig. 3 and Additional file 8: Figure S4) might illustrate a difference in species' responses to habitat availability during the transition from the LIG into the last glacial period, reflecting the possibility that their specific climatic and environmental tolerances were associated with the breadth of their ecological niches [3]. For example, precipitation in the warmest quarter (Bio_18) is the most influential bioclimatic variable in present-day ENM prediction for all five of the species with early population growth, but makes a secondary contribution for the other species with late growth (Additional file 1: Table S3).

\section{Conclusions}

Our study demonstrates that the conventional views of glacial contraction and interglacial expansion for mesicadapted species cannot be applied to all the earth's climatic zones. In East Asia, subtropical avifauna showed narrower distribution and smaller $N_{e}$ at the LIG and then bounced back to a larger LGM range similar to the current one. The asynchronous range dynamics among organisms in different ecozones might have led to variable evolutionary consequences. For example, at the LGM temperate species might have retreated to isolated refugia facilitating population divergence and speciation $[1,65]$, while subtropical species might have expanded their ranges with increasing gene flow and obscuring differentiation among populations. Therefore, a comprehensive assessment of regional differences is critical to test historical biogeographic hypotheses globally.

This study also suggests that high climatic variation, rather than high mean temperatures, explain the potential range contraction of subtropical birds at the LIG. The LIG climate might reflect the near future climate characterized by increased climatic variation under the impact of global warming [61, 64]. Accordingly, we can predict that a continuing trend of climate warming will pose a serious threat to subtropical biodiversity and thus justifies more conservation attention.

\section{Additional files}

Additional file 1: Table S1. Detailed information for each species. Table S2. Summary of key statistics for sequences of each studied species. Table S3. Detailed information for ENM analyses. This includes estimates of model fit and the relative percentage contributions of the climatic variables to the ENM models for each species studied. (DOCX $68 \mathrm{~kb}$ )

Additional file 2: Raw occurrence dataset for the 11 birds studied. (XLS $403 \mathrm{~kb}$ )

Additional file 3: Occurrence data after rarefaction for the 11 birds studied. (XLS 266 kb)

Additional file 4: Figure S1. Ecological niche models (ENM) and distribution dynamics. (A) Aegithalos concinnus, (B) Cettia fortipes, (C) Leiothrix lutea, (D) Pomatorhinus ruficollis, (E) Stachyridopsis ruficeps, (F) Alcippe morrisonia, $(\mathrm{G})$ Spizixos semitorques, $(\mathrm{H})$ Fulvetta ruficapilla, (I) Lioparus chrysotis and (J) Parus monticolus (K) Yuhina diademata. For each species, three time points were considered, i.e., the present day (Present), last glacial maximum (LGM; 26-19 thousand years ago, Ka), and last interglacial period (LIG; 132-112 Ka). Black dots show species occurrence records rarefied at a $5-\mathrm{km}$ spatial resolution. To avoid over-prediction, the ENMs were transformed to binary (presence/ absence) distribution by a threshold of the maximum training sensitivity plus specificity. (PDF 9168 kb)

Additional file 5: Figure S2. Histograms indicating comparisons of ten climatic variables among LIG, LGM and Present. The means of each variable was calculated based on 1506 occurrence records after spatial filtration at $5 \mathrm{~km}$ of all the combination records of 11 birds. The temperature data are in centigrade $\left({ }^{\circ} \mathrm{C}\right)$ and precipitation is in millimeters $(\mathrm{mm})$. The asterisk $\left({ }^{*}\right)$ indicates $P \leq 0.001$ calculated with a paired-samples $T$ test. The results show larger seasonal climatic variability at the LIG than the LGM or the present, being warmer in summers (Bio_5), colder in winters (Bio_11), drier in dry seasons (Bio_14) and wetter in wet seasons (Bio_16). (PDF 407 kb) 
Additional file 6: Figure S3. Relations between climatic indices (y axis) and latitudes ( $x$ axis) at LIG. The temperature data are in centigrade, precipitation is in millimeters and the latitudes are in degrees. The results show that annual temperature variations increased while winter precipitation and temperature decreased toward the north at the LIG. (PDF $1576 \mathrm{~kb}$ )

Additional file 7: The raw sequence data generated in the study. (TXT $5410 \mathrm{~kb})$

Additional file 8: Figure S4. Demographic reconstruction of the most favored models for each bird studied at original (a) and 10-fold (b) molecular rates. The colored plot lines represent median posterior estimates of the product of effective population size $\left(N_{e}\right)$ and generation time $(g)$. Times are in thousands of years before present (Ka). Timeframes are marked by grey areas. LIG, last interglacial period, 112-132 Ka; LGM, last glacial maximum, $\sim 19-26 \mathrm{Ka}$. (PDF $476 \mathrm{~kb})$

\section{Abbreviations}

AUC: The area under the receiver operating characteristic curve; ENM: Ecological niche model; Ka: Thousand years ago: LGM: Last glacial maximum; LIG: Last interglacial period; MTSS: The maximum training sensitivity plus specificity; $\mathrm{N}_{e}$ : Effective population sizes

\section{Acknowledgements}

The authors would like to deeply thank Pei-Jen L. Shaner and Shang-Fang Yang, all the anonymous reviewers and Dr. Craig Moritz and other editors, for valuable comments on the manuscript. We are also grateful to Alan Watson who had improved the readability of this manuscript.

\section{Funding}

This work was supported by the National Natural Science Foundation of China (31,540,092 and 31,101,636 to F.D.) and Yunnan Applied Basic Research Project (2016FA043 to X.J.Y.). The funding bodies take no part in the design of the study and collection, analysis, and interpretation of data and in writing the manuscript.

\section{Availability of data and materials}

The occurrence records used in the ecological niche modeling analyses are appended as Additional files 2 and 3. All the DNA sequences generated have been submitted to GenBank (accession numbers: KY434671-KY435354, KY437041-KY437069, KY597864-KY604704).

\section{Authors' contributions}

FD, YXJ, LSH and LFM conceived the ideas. FD, FW, LFM, LSH collected DNA samples. FD, XLL, CMH, JYG and QZ analyzed the data. All authors contributed to the writing of the paper, with major input from FD and $\mathrm{CMH}$. All authors read and approved the final manuscript.

\section{Ethics approval and consent to participate}

The specimen collections and laboratory work were carried out under license (NO. SMKX2016-023) approved by Kunming Institute of Zoology, Chinese Academy of Sciences.

\section{Consent for publication}

Not applicable.

\section{Competing interests}

The authors declare that they have no competing interests.

\section{Publisher's Note}

Springer Nature remains neutral with regard to jurisdictional claims in published maps and institutional affiliations.

\section{Author details}

${ }^{1}$ Kunming Institute of Zoology, Chinese Academy of Sciences, 32 Jiaochang Donglu Rd., Kunming, Yunnan, China. ${ }^{2}$ Department of Life Science, National Taiwan Normal University, 88 Ting-chou Rd., Sec. 4, Taipei 116, Taiwan. ${ }^{3}$ Biodiversity Research Center, Academia Sinica, Taipei, Taiwan. ${ }^{4}$ Guangdong Institute of Applied Biological Resources, Guangzhou 510260, China. ${ }^{5}$ Key Laboratory of Zoological Systematics and Evolution, Institute of Zoology,
Chinese Academy of Sciences, 1 Beichen West Rd., Chaoyang District, Beijing 100101, China.

Received: 4 July 2017 Accepted: 28 November 2017

Published online: 06 December 2017

\section{References}

1. Hewitt GM. Genetic consequences of climatic oscillations in the quaternary. Phil Trans R Soc Lond B. 2004:359:183-59.

2. Provan J, Bennett KD. Phylogeographic insights into cryptic glacial refugia. Trends Ecol Evol. 2008:23:564-71.

3. Stewart JR, Lister AM, Barnes I, Dalén L. Refugia revisited: individualistic responses of species in space and time. Phil Trans R Soc Lond B. 2010;277: $661-71$

4. Keppel G, Van Niel KP, Wardell-Johnson GW, Yates CJ, Byrne M, Mucina L, et al. Refugia: identifying and understanding safe havens for biodiversity under climate change. Glob Ecol Biogeogr. 2012;21:393-404.

5. Shafer ABA, Cullingham $\mathrm{Cl}$, Côté SD, Coltman DW. Of glaciers and refugia: a decade of study sheds new light on the phylogeography of northwestern North America. Mol Ecol. 2010;19:4589-621.

6. Fraser Cl, Nikula R, Ruzzante DE, Waters JM. Poleward bound: biological impacts of southern hemisphere glaciation. Trends Ecol Evol. 2012;27:462-71.

7. Anhuf D, Ledru MP, Behling H, Da Cruz Jr FW, Cordeiro RC, Van der Hammen T, et al. Paleo-environmental change in Amazonian and African rainforest during the LGM. Palaeogeogr Palaeocl. 2006;239:510-27.

8. Kearns AM, Joseph L, Toon A, Cook LG. Australia's arid-adapted butcherbirds experienced range expansions during Pleistocene glacial maxima. Nat Commun. 2014:5:3994

9. Raes N, Cannon CH, Hijmans RJ, Piessens T, Saw LG, van Welzen PC, et al. Historical distribution of Sundaland's Dipterocarp rainforests at quaternary glacial maxima. Proc Natl Acad Sci U S A. 2014;111:16790-5.

10. Peterson AT, Ammann CM. Global patterns of connectivity and isolation of populations of forest bird species in the late Pleistocene. Glob Ecol Biogeogr. 2013;22:596-606.

11. Harrison SP, Yu G, Takahara H, Prentice IC. Palaeovegetation: diversity of temperate plants in East Asia. Nature. 2001;413:129-30.

12. Shi YF, Ren BG, Wang JT, Derbyshire E. Quaternary glaciation in China. Quat Sci Rev. 1986;5:503-7.

13. Qu YH, Zhang RY, Quan Q, Song G, Li SH, Lei FM. Incomplete lineage sorting or secondary admixture: disentangling historical divergence from recent gene flow in the vinous-throated parrotbill (Paradoxornis wevvianus). Mol Ecol. 2012:21:6117-33.

14. Qu YH, Ericson PGP, Quan Q, Song G, Zhang RY, Gao B, et al. Long-term isolation and stability explain high genetic diversity in the eastern Himalaya. Mol Ecol. 2014;23:705-20.

15. Fang F, Sun HY, Zhao Q, Lin CT, Sun YF, Gao W, et al. Patterns of diversity, areas of endemism, and multiple glacial refuges for freshwater crabs of the genus Sinopotamon in China (Decapoda: Brachyura: Potamidae). PLoS One. 2013:8:e53143

16. Zhao N, Dai CY, Wang WJ, Zhang RY, Qu YH, Song G, et al. Pleistocene climate changes shaped the divergence and demography of Asian populations of the great tit Parus major: evidence from phylogeographic analysis and ecological niche models. J Avian Biol. 2012;43:297-310.

17. Wang WJ, McKay BD, Dai CY, Zhao N, Zhang RY, Qu YH, et al. Glacial expansion and diversification of an east Asian montane bird, the green-tit (Parus monticolus). J Biogeogr. 2013;40:1156-69.

18. Hosner PA, Liu HT, Peterson AT, Moyle RG. Rethinking phylogeographic structure and historical refugia in the rufous-capped babbler Cyanoderma Ruficeps in light of range-wide genetic sampling and paleodistributional reconstructions. Curr Zool. 2015;61:901-9.

19. Lim HC, Zou FS, Sheldon FH. Genetic differentiation in two widespread, open-forest bird species of Southeast Asia (Copsychus saularis and Megalaima haemacephala): insights from ecological niche modeling. Curr Zool. 2015:61:922-34.

20. Quan Q, Qu YH, Lei FM. Genetic diversification in the east Himalayas as revealed by comparative phylogeography of the black-throated bushtit and Elliot's laughing thrush. Curr Zool. 2015;61:935-42.

21. Bai WN, Wang WT, Zhang DY. Constrasts between the phylogeographic patterns of chloroplast and nuclear DNA highlight a role for pollenmediated gene flow in preventing population divergence in an East Asian template tree. Mol Phylogenet Evol. 2014;81:37-48. 
22. Bai WN, Wang WT, Zhang DY. Phylogeographic breaks within Asian butternuts indicate the existence of a phytogeographic divide in East Asia. New Phytol. 2016;209:1757-72.

23. Reddy S, Nyári ÁS. Novel insights into the historical biogeography of the streak-breasted scimitar babbler complex (Aves: Timaliidae: Pomatorhinus ruficollis Complex). Curr Zool. 2015;61:910-21.

24. Lyu N, Päckert M, Tietze DT, Sun YH. Uncommon paleodistribution patterns of Chrysolophus pheasants in east Asia: explanation and implications. J Avian Biol. 2015;46:528-37.

25. Arenas M, Ray N, Currat M, Excoffier L. Consequences of range contractions and range shift on molecular diversity. Mol Biol Evol. 2012;29:207-18.

26. Yan F, Zhou WW, Zhao HT, Yuan ZY, Wang YY, Jiang K, et al. Geological events play a larger role than Pleistocene climatic fluctuations in driving the genetic structure of Quasipaa boulengeri (Anura: Dicroglossidae). Mol Ecol. 2013:22:1120-33.

27. Ho SYW, Shapiro B. Skyline-plot methods for estimating demographic history from sequence nucleotide sequences. Mol Ecol Resour. 2011;11:423-34.

28. Li SH, Yeung CKL, Feinstein J, Han LX, Le MH, Wang CX, et al. Sailing through the late Pleistocene: unusual historical demography of an east Asian endemic, the Chinese Hwamei (Leucodioptron canorum canorum), during the last glacial period. Mol Ecol. 2009;18:622-33.

29. Carling MD, Brumfield RT. Gene sampling strategies for multi-locus population estimates of genetic diversity $(\theta)$. PLoS One. 2007;2:e160.

30. Pigot $A L$, Owens IPF, Orme CDL. The environmental limits to geographic range expansion in birds. Ecol Lett. 2010;13:705-15.

31. Excoffier $L$, Foll M, Petit RJ. Genetic consequences of range expansions. Annu Rev Ecol Evol Syst. 2009;40:481-501.

32. Brown JL. SDMtoolbox: a python-based GIS toolkit for landscape genetic, biogeographic, and species distribution model analyses. Methods Ecol Evol. 2014;5:694-700.

33. Hijmans RJ, Cameron SE, Parra JL, Jones PG, Jarvis A. Very high resolution interpolated climate surfaces for global land areas. Int J Climatol. 2005;25: 1965-78.

34. Barve N, Barve V, Jiménez-Valverde A, Lira-Noriega JA, Maher SP, Peterson AT. The crucial role of the accessible area in ecological niche modeling and species distribution modeling. Ecol Model. 2011;222:1810-9.

35. Olson DM, Dinerstein E, Wikramanayake ED, Burgess ND, Powell GVN, Underwood EC, et al. Terrestrial ecoregions of the world: a new map of life on earth. Biosciences. 2001;51:933-8.

36. Phillips SJ, Anderson RP, Schapire RE. Maximum entropy modeling of species geographic distributions. Ecol Model. 2006;190:231-59.

37. Hijmans RJ, Guarino LG, Bussink C, Mathur P, Cruz M, Barrentes I. et al. DIVA-GIS. Version 7.5. A geographic information system for the analysis of species distribution data. 2005. Manual available at http://www.diva-gis.org. Accessed Mar 2016

38. Felsenstein J. Accuracy of coalescent likelihood estimates: do we need nore sites, more sequences, or more loci? Mol Biol Evol. 2006;23:691-700.

39. Sambrook E, Fritsch F, Maniatis T. Molecular cloning. Cold Spring Harbor: Cold Spring Harbor Press; 1989.

40. Backström N, Fagerberg S, Ellegren H. Genomics of natural bird populations: a gene-based set of reference markers evenly spread across the avian genome. Mol Ecol. 2008;17:964-80.

41. Gao B, Qu YH, Song G, Liu HT, Lei FM. Anonymous single-copy nuclear DNA (scnDNA) markers for grey-cheeked fulvetta (Alcippe morrisonia) and rufouscapped babbler (Stachyridopsis ruficeps). Conserv Genet Resour. 2012;4:777-81.

42. Shanner PJL, Tsao TH, Lin EC, Liang W, Yeh CF, Yang XJ, et al. Climate niche differentiation between two passerines despite ongoing gene flow. J Anim Ecol. 2015;84:829-39.

43. Thompson JD, Gibson TJ, Plewniak F, Jeanmougin F, Higgins DG. The Clustal X windows interface: flexible strategies for multiple sequence alignment aided by quality analysis tools. Nucleic Acids Res. 1997:25:4876-84.

44. Stephens M, Donelly P. A comparison of Bayesian methods for haplotype reconstruction form population genotype data. Am J Hum Genet. 2003;73:1162-9.

45. Harrigan RJ, Mazza ME, Sorenson MD. Computation vs. cloning: evaluation of two methods for haplotype determination. Mol Ecol Resour. 2008:8:1239-48.

46. Martin D, Rybicki E. RDP: detection of recombination amongst aligned sequences. Bioinformatics. 2000;16:562-3.

47. Tajima F. Statistical method for testing the neutral mutation hypothesis by DNA polymorphism. Genetics. 1989;123:585-95.

48. Fu YX, Li WH. Statistical tests of neutrality of mutations. Genetics. 1993;133:693-709.
49. Librado P, Rozas J. DnaSP v5: a software for comprehensive analysis of DNA polymorphism data. Bioinformatics. 2009:25:1451-2.

50. Drummond AJ, Suchard MA, Xie D, Rambaut A. Bayesian phylogenetics with BEAUti and the BEAST 1.7. Mol Biol Evol. 2012;29:1969-73.

51. Gill MS, Lemey P, Faria NR, Rambaut A, Shapiro B, Suchard MA. Improving Bayesian population dynamics inference: a coalescent-based model for multiple loci. Mol Biol Evol. 2013;30:713-24.

52. Beale CM, Lennon JJ. Incorporating uncertainty in predictive species distribution modeling. Phil Trans R Soc Lond B. 2012;367:247-58.

53. Kass RE, Raftery AE. Bayes factors and model uncertainty. J Am Statist Ass. 1995;90:773-95.

54. Lambert DM, Ritchie PA, Millar CD, Holland B, Drummond AJ, Baroni C. Rates of evolution in ancient DNA from Adélie penquin. Science. 2002;295:2270-3.

55. Ho SYW. The changing face of the molecular evolutionary clock. Trends Ecol Evol. 2014:29:496-503.

56. Molak M, Ho SYW. Prolonged decay of molecular rate estimates for metazoan mitochondrial DNA. Peer J. 2015:3:e821.

57. Zhang G, Li C, Li Q, Li B, Larkin DM, Lee C, et al. Comparative genomics reveals insights into avian genome evolution and adaptation. Science. 2014;346:1311-20.

58. Rambaut A, Suchard M, Drummond A. Tracer v.1.6. 2013. Available at http:// tree.bio.ed.ac.uk/software/tracer/. Accessed Mar 2016.

59. Kuhner MK. LAMARC 2.0, maximum likelihood and Bayesian estimation of population parameters. Bioinformatics. 2006;22:768-70.

60. Qian H, Ricklefs RE. Palaeovegetation (communications arising): diversity of temperate plants in east Asia. Nature. 2001;413:129-30.

61. Otvos EG. The last interglacial stage: definitions and marine highstand. North America and Eurasia Quat Int. 2015;383:158-73.

62. Tyrberg T. Avifaunal responses to warm climate: the message from last interglacial faunas. Rec Aust Mus. 2010;62:193-205.

63. Kim SJ, LV JM, Yi SH, Choi T, Kim BM, Lee BY, et al. Climate response over Asia/Arctic to change in orbital parameters for the last interglacial maximum. Geosci J. 2010;14:173-90.

64. Vasseur DA, DeLong JP, Gilbert B, Greig HS, Harley CDG, McCann KS, et al. Increased temperature variation poses a greater risk to species than climate warming. Proc R Soc B. 2014;281:20132612.

65. Byrne M, Yeates DK, Joseph L, Kearney M, Bowler J, Williams MA, et al. Birth of a biome: insights into the assembly and maintenance of the Australian arid zone biota. Mol Ecol. 2008;17:4398-417.

\section{Submit your next manuscript to BioMed Central and we will help you at every step:}

- We accept pre-submission inquiries

- Our selector tool helps you to find the most relevant journal

- We provide round the clock customer support

- Convenient online submission

- Thorough peer review

- Inclusion in PubMed and all major indexing services

- Maximum visibility for your research

Submit your manuscript at www.biomedcentral.com/submit
Biomed Central 